\title{
The Furan Approach to the Synthesis of the $(+)$-Civet Constituent (+)-2-((2S,6S)-6- Methyltetrahydro-2H-Pyran-2-yl) Acetic Acid
}

\section{Isela García ${ }^{1}$, Alioune Fall ${ }^{2}$, Fátima Garrido ${ }^{1}$, Mohamed Gaye ${ }^{2}$, Generosa Gómez ${ }^{1 *}$ and Yagamare Fall ${ }^{1 *}$} ${ }^{1}$ Departamento de Química Orgánica, Facultad de Química and Instituto de Investigación Sanitaria Galicia Sur (IISGS), University of Vigo, Spain ${ }^{2}$ Laboratoire de Chimie de Coordination Organique (LCCO), Département de Chimie, Faculté des Sciences et Techniques: Université Cheikh Anta Diop de Dakar, Sénégal, Africa

Submission: October 31, 2017; Published: November 21, 2017

*Corresponding author: Yagamare Fall, Departamento de Química Orgánica, Facultad de Química and Instituto de Investigación Sanitaria Galicia Sur (IISGS), University of Vigo, Spain, Email: yagamare@uvigo.es

\section{Abstract}

We describe an efficient new approach for the synthesis of the civet constituent (2S,6S)-(6-Methyltetrahydropyran-2-yl) acetic acid from commercially available starting material using the furan approach, a methodology we developed some years ago, which is based on the oxidation of a furan ring with singlet oxygen followed by an intramolecular hetero Michael addition.

Results and Discussion: We report herein a synthesis of 1 using the furan approach [1], a method we developed in 2003 and which proved to be a very powerful tool in the field of natural products synthesis. Furan 2 was chosen as chiral starting material and was synthesized according to (scheme 1). Commercially available chiral hydroxyester 3 reacted with TBDPSCl to give 4 in $99 \%$ yields. Hydrolysis of ester 4 with Dibal afforded $99 \%$ yield of alcohol 5 which was easily converted into iodide 6 [2]. Lithiation of furan 7 and reaction with 6 afforded the targeted alkylated furan 2. Oxidation of furan 2 with singlet oxygen followed by treatment with acetic anhydride in pyridine, lead to butenolide 8 (Scheme 2). Removal of the TBDPS group of 8 with TBAF afforded a mixture of unseparable bicyclic lactones 9 and 10 through an intramolecular Michael addition ( $92 \%$ ).

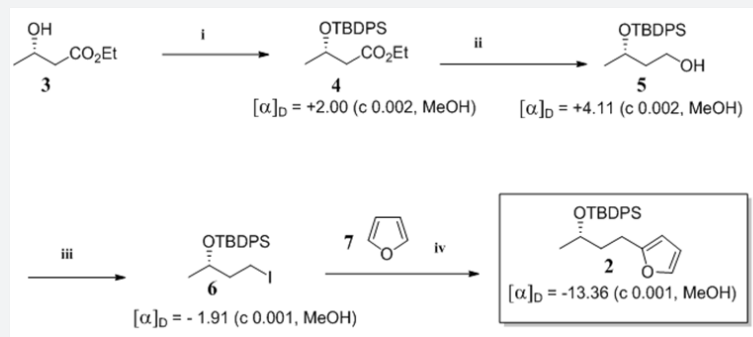

Scheme 1: Reagents and conditions: (i) TBDPSCl, Imid, DMF (99\%); (ii) Dibal, $\mathrm{CH} 2 \mathrm{Cl} 2,-78^{\circ} \mathrm{C}(99 \%)$; (iii) PPh3, I2, Imid, $\mathrm{THF}, 0^{\circ} \mathrm{C}(99 \%)$; (iv) 7 , bipy, nBuLi, THF, $0{ }^{\circ} \mathrm{C}$ to rt $(99 \%)$.

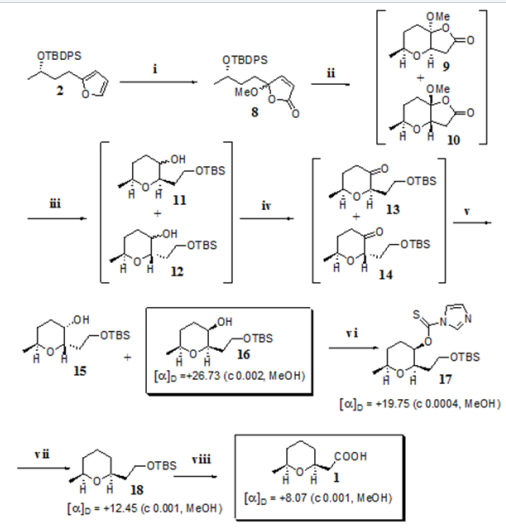

Scheme 2: Reagents and conditions: (i) a) $102, \mathrm{MeOH}$, rose bengal, hv; b) Ac2O, py, DMAP (99\%, two steps); (ii) TBAF, THF, rt (92\%); (iii) a) LAH, BF3.OEt2 (99\%); a) TBSCI, Imid, THF (99\%); (iv) TPAP, NMO, CH2Cl2 (55\%); (v) L-Selectride, THF, $-78^{\circ} \mathrm{C}[79 \% 15$ (32\%), 16 (47\%)]; (vi) Im2CS, THF, reflux (81\%); (vii) n-Bu3SnH, AIBN, reflux (35\%); (viii) CrO3, Acetone (78\%). 
Opening of lactones 9 and 10 with LiAlH4 in the presence of BF3.OEt2 gave a mixture of 4 diastereoisomeric alcohols 11 and 12 which were oxidized with TPAP to afford two unseparable diastereoisomeric ketones 13 and 14 . Ketones 13 and 14 were stereoselectively reduced to alcohols 15 (32\%) and 16 (47\%) using L-Selectride. Diastereoisomeric alcohols 15 and 16 were easily separable by column chromatography using 2\% EtOAc/Hexane as eluent. The relative stereochemistry of 15 and 16 was established by Noe experiments on the corresponding acetates 15 a and 16a (Figures 1 \& 2). Radical deoxygenation [3] of alcohol 16 led to cis-1,6-disubstituted tetrahydropyran 18 which upon oxidation with Jones reagent afforded the target compound 1 . Noteworthy mentioning the direct oxidation of silylether 18 into carboxylic acid 1 without the need for deprotection of the primary hydroxy group [4].

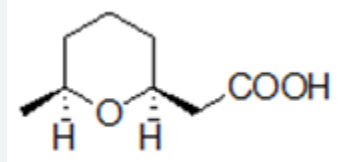

1

Figure 1.

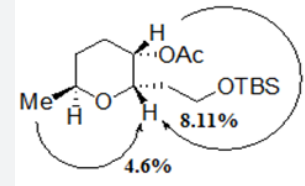

$15 \mathbf{a}$

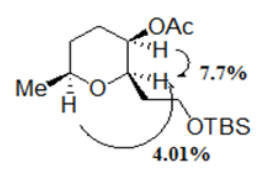

$16 \mathrm{a}$

Figure 2: NOE correlations for 15a and 16a.

Conclusion: A new and efficient method for the enantioselective synthesis of (2S,6S)-(6-Methyltetrahydropyran-2-yl) acetic acid 1 from commercially available chiral hydroxyester 3 is described. This synthesis enlarges the scope of our developed methodology for the synthesis of oxacyclic systems. The use of this methodology for the synthesis of various natural products is now under way in our laboratories.

Keywords: Singlet Oxygen; Butenolide; Tetrahydropyran; Civet Cat Compound; Natural Product

\section{Introduction}

The THP-ring backbone is present in many natural products of biological and pharmacological significance [5]. (+)-2-(2S,6S)(6-Methyltetrahydro-2H-pyran-2-yl)acetic acid 1 (Figure 1) is an expensive perfume material which was isolated by Maurer and coworkers in 1978 from the perianal glandular pheromone secretion of the African civet (Viverracivetta) [6]. Civet is, together with musk, ambergris and castoreum, one of the few very expensive animal perfume materials [7]. This compound has attracted much attention owing to its synthetically interesting cis-2,6-disubstituted tetrahydropyran moiety and several syntheses of racemic and optically pure 1 have been reported [8].

\section{Acknowledgement}

The work of the NMR and MS divisions of the research support services of the University of Vigo (CACTI) is gratefully acknowledged. AF and MG thank the University Cheikh Anta Diop (Dakar) for financial support for a research stay at the University of Vigo.

\section{References}

1. (a) Y Fall, B Vidal, D Alonso, G Gómez (2003) Tetrahedron Lett 44: 4467-4469; (b) M Pérez, P Canoa, G Gómez, C Terán, Y Fall (2004) Tetrahedron Lett 45: 5207-5209; (c) D Alonso, M Pérez, G Gómez, B Covelo, Y Fall (2005) Tetrahedron 61: 2021-2026; (d) M Teijeira, PL Suárez, G Gómez, C Terán, Y Fall (2005) Tetrahedron Lett 46 5889-5892; (e) I García, G Gómez, M Teijeira, C Terán, Y Fall (2006)
Tetrahedron Lett 47: 1333-1335; (f) P Canoa, M Pérez, B Covelo, G Gómez, Y Fall (2007) Tetrahedron Lett 48: 3441-3443; (g) C Álvarez, M Pérez, A Zúñiga, G Gómez, Y Fall (2010) Synthesis 22: 3883-3890; (h) P Canoa, Z Gándara, M Pérez, R Gago, G Gómez, Y Fall (2011) Synthesis 3: 431-436; (h) M Gónzalez, Z Gándara, B Covelo, G Gómez, Y Fall (2011) Tetrahedron Lett 52: 5983-5986; (i)A Zúñiga, G Pazos, P Besada, Y Fall (2012) Tetrahedron Lett 53: 4293-4295; (j) M González, Z Gándara, G Pazos, G Gómez, Y Fall (2013) Synthesis 45: 625-632; (k) M Gónzalez, Z Gándara, A Martínez, G Gómez, Y Fall (2013) Tetrahedron Lett 54: 3647-3650; (I) M Gónzalez, Z Gándara, A Martínez, G Gómez, Y Fall (2013) Synthesis 45: 1693-1700; M González, Z Gándara, M Seck, G Gómez, Y Fall (2015) Mediterr J Chem 4: 18-29.

2. Pérez Sestelo J, Mascareñas J L, Castedo L, Mouriño A (1993) J Org Chem 58: 118-123.

3. RajanBabu TV, Fukunaga T, Reddy GS (1989) J Am Chem Soc 111: 17591769.

4. Andrew Evans P, Roseman JD, Garber LT (1996) J Org Chem 61: 48804881.

5. (a) Muzart J (2010) J Mol Catal A: Chem 319: 1-29; (b) I Larrosa, P Romea, F Urpi (2008) Tetrahedron 64: 2683-2723; (c) PA Clarke, S Santos (2006) Eur J Org Chem pp. 2045-2053; (d) Y Tang, J Oppenheimer, Z Song, L You, X Zhang, et al. (2006) Tetrahedron 62: 10785-10813; (e) J Muzart (2005) Tetrahedron 61: 5955-6008; (f) EJ Kang, E Lee (2005) Chem Rev 105: 4348-4378; (g) E Álvarez, ML Candenas, R Pérez, JL Ravelo, JD Martin (1995) Chem Rev 95: 19531980; (h) YM Shimizu (1993) Chem Rev 93: 1685-1698.

6. B Maurer, A Grieder, W Thommen (1979) Helv Chim Acta 62: 44-47.

7. E Lederer (1950) In Progress in the Chemistry of Organic Natural Products; Zechmeister L. Ed: Springer: Vienna. 
8. (a) XH Yang, K Wang, SF Zhu, JH Xie, QL Zhou (2014) J Am Chem Soc 136: 17426-17429; (b) S Sultan, K Indukuri, MJ Deka, AK Saikia (2013) J Org Chem 78: 12182-12188; (c) O Karlubikova, M Babjak, T Gracza (2011) Tetrahedron 67: 4980-4987; (d) MO Brien, S Cahill, LA Evans (2008) Chem Commun pp. 5559-5561; (e) S Mori, S Iwamoto, S Yamauchi (2006) Biosci Biotechnol Biochem 70: 712-717; (f) RJ Hinkle, Y Lian,
ND Litvinas, AT Jenkins, DC Burnette (2005) Tetrahedron 61: 1167911685; (g) MC Carreño, R des Mazery, A Urbano, F Colobert, G Solladié (2003) J Org Chem 68: 7779-7787; (h) DJ Dixon, SV Ley, EW Tate (2000) J Chem Soc, Perkin Trans 1: 2385-2394; (i) AJF Edmunds, W Trueb (1997) Tetrahedron Lett 38: 1009-1012; (j) T Mandai, M Ueda, K Kashiwagi, M Kawada, J Tsuji (1993) Tetrahedron Lett 34: 111-114.

\section{Your next submission with Juniper Publishers will reach you the below assets}

- Quality Editorial service

- Swift Peer Review

- Reprints availability

- E-prints Service

- Manuscript Podcast for convenient understanding

- Global attainment for your research

- Manuscript accessibility in different formats ( Pdf, E-pub, Full Text, Audio)

- Unceasing customer service

Track the below URL for one-step submission https://juniperpublishers.com/online-submission.php 